

\section{Fetal Dural Sinus Thrombosis: A Systematic Review}

Running title: Fetal Dural Sinus Thrombosis

Adalina Sacco ${ }^{1,2^{\star}}$, Deepika Pannu ${ }^{2}$, Fred Ushakov ${ }^{2}$, Leigh Dyet $^{3}$, Pranav Pandya $^{1,2}$

${ }^{1}$ Institute for Women's Health, University College London, London, UK

${ }^{2}$ Fetal Medicine Unit, University College London Hospitals, London, UK

${ }^{3}$ Department of Neonatology, University College London Hospitals, London, UK

*Correspondence: a.sacco@ucl.ac.uk

Fetal Medicine Unit, $1^{\text {st }}$ Floor, EGA Wing, University College London Hospital, 25 Grafton Way, Fitzrovia, London WC1E 6DB

Conflict of interest statement:

All authors report no conflict of interest

Funding:

None

Ethics:

Ethical approval was not required as pre-published, anonymised data only was used.

Data Statement:

The data that support the findings of this study are available from the corresponding author upon reasonable request.

This article has been accepted for publication and undergone full peer review but has not been through the copyediting, typesetting, pagination and proofreading process which may lead to differences between this version and the Version of Record. Please cite this article as doi: $10.1002 / \mathrm{pd} .5869$ 


\section{Abstract}

\section{Introduction}

Fetal dural sinus thrombosis (DST) is a rare condition. Although numerous case reports exist, the findings appear heterogenous and providing accurate patient counselling remains challenging.

\section{Methods}

A systematic literature review was conducted in accordance with PRISMA guidance ${ }^{1}$.

\section{Results}

Thirty-one studies including 78 patients were included in this review. No association with maternal or neonatal coagulopathy, infection or trauma was found. The average gestational age at diagnosis was 25 weeks (range 17-34 weeks). Approximately half of foetuses affected were female (48.7\%); one quarter were male (25.6\%) and one quarter had no sex stated (25.6\%). Termination of pregnancy was chosen in $25.6 \%$ of cases (20/78). In continuing pregnancies,10.3\% (6/58) experienced a perinatal death. Antenatally, the majority of lesions either decreased in size (38.5\%) or completely resolved $(32.7 \%)$. The neonatal or childhood outcome was normal in $88.0 \%$ of survivors (44/50). The average age at follow up was 16.4 months, ranging from birth to 6 years.

\section{Conclusion}

This review found that ten percent of DST cases experience in-utero or neonatal death. In survivors, the majority of cases reduce in size or completely resolve in 
pregnancy and $85 \%$ are reported to have a good outcome. However, further evidence is needed regarding long-term neurocognitive sequelae.

Keywords:

Fetal dural sinus thrombosis, fetal dural sinus malformation, torcular herophili

What's already known on this topic?

- Thrombosis of the dural sinus can be diagnosed in fetal life

- Several case reports exist in the literature

- Findings appear heterogenous and it remains challenging to provide accurate patient counselling on this condition

What does this study add?

- This is the only systematic review of this subject and the largest collection of patients published (78)

- Approximately ten percent of ongoing pregnancies experience a perinatal death

- The majority of lesions decrease in size or resolve in pregnancy

- The neonatal or childhood outcome is normal in the majority of cases

- Further evidence is needed regarding long-term neurocognitive sequelae 


\section{$\underline{\text { Introduction }}$}

Fetal dural sinus thrombosis (DST), also known as dural venous sinus ectasia or torcula herophili, is a rare condition. Within the brain, superficial and deep veins drain blood and empty into dural venous sinuses within the subarachnoid space. These sinuses anastomose posteriorly at the confluence of sinuses, which is also known as the torcular herophili (Figure 1). This area is a focal point for venous thrombosis and, if a thrombus is occlusive, obstruction can occur with subsequent development of a dural lake. Thrombosis within the dural venous sinuses can be diagnosed in childhood or adult life, when there is an association with thrombophilias, infection, blood disorders such as polycythaemia and trauma ${ }^{2}$. It affects approximately 0.67 per 100,000 children per year ${ }^{3}$. The incidence of fetal occurrence is unknown, although several case reports exist. Antenatal findings suggestive of DST on ultrasound are the visualisation of a hypoechogenic posterior fossa mass with or without a focal hyperechoic area within (Figure 2 a-d). Findings from published case reports appear heterogenous and it remains challenging to provide accurate patient counselling on this condition. We therefore sought to systematically review the literature on this topic and produce a comprehensive summary of current knowledge to aid clinicians and patients facing this diagnosis. 
Methods

Protocol and Registration

This systematic review was conducted in accordance with the Preferred Reporting Items for Systematic reviews and Meta-analyses (PRISMA) guidance ${ }^{1}$. The protocol was registered with the International Prospective Register of Systematic Reviews (PROSPERO- CRD42019147205).

\section{Eligibility criteria}

All studies of dural sinus thrombosis in humans diagnosed antenatally were considered eligible. Thromboses in another part of the venous circulation were excluded. As this condition was believed to be rare, case reports $(n \leq 3)$ were included as well as observational studies (cohort and case-control) and randomised trials. Systematic and narrative reviews were excluded after checking reference lists for primary studies. Publications from 1990 to July 2019 were considered eligible and no language restrictions were applied.

\section{Search strategy}

A systematic review was conducted in MEDLINE, EMBASE and Cochrane databases using free text as follows:

F(o)etal OR Prenatal OR antenatal OR neonatal OR infant AND:

- dural venous sinus thrombosis

- dural venous sinus ectasia

- dural venous sinus malformation

- torcular herophili 
None of these terms were Medical Subject Headings (MESH). Subsequently, a grey literature (first 100 hits in Google Scholar and Pubmed) search was performed, and reference lists of relevant review articles were manually checked. Covidence software (Veritas Health Innovation Ltd, Melbourne, Australia) was used to eliminate duplicate articles and manage study screening.

\section{Study selection}

Two authors (A.S. and D.P.) independently screened all studies by title and abstract and subsequently assessed full-text articles. Disagreements were resolved by consensus.

\section{Data extraction}

Two authors (A.S. and D.P.) independently extracted data from all studies and entered them into a standardised Excel (Microsoft, Washington, USA) form. Data which did not match was discussed and the study re-visited to reach a consensus.

\section{Quality assessment of studies}

Two authors (A.S. and D.P.) assessed study quality and risk of bias independently using a standardised Excel form. An adaptation of the Murad tool ${ }^{4}$ for case series and case reports was used - specifically, domains relating to challenge/ rechallenge phenomenon and dose-response effect were omitted as these were not relevant to the condition studied.

\section{Statistics}

Due to the anticipated rarity of the condition, meta-analysis was not planned. 
$\underline{\text { Results }}$

\section{Study selection}

The electronic literature search identified 172 studies (Figure 3); search of the grey literature and reference lists identified a further five studies. Following import of the literature search results, 102 studies were removed as duplicates and the 75 remaining studies were screened by title and abstract. A further 32 were included as irrelevant and full texts of the remaining 43 articles were reviewed. Twelve studies were excluded for the following reasons: neonatal or paediatric population (8), insufficient information or full text unavailable (2), thrombosis not confirmed (1) and duplicate study (1). Eventually 31 studies were included in this systematic review.

\section{Study characteristics}

Characteristics of included studies are shown in Table 1. Case reports made up the majority of studies $(26 / 31,83.9 \%)$; the remainder were case series $(5 / 31,16.1 \%)$. A total of 78 patients were included in this systematic review.

Quality assessment

Quality assessment of included studies is given in Figure 4. The majority of studies $(28 / 31,90.3 \%)$ were high quality for the type of study assessed (case studies and series). The remaining studies $(3 / 31,9.7 \%)$ were low quality. Length of follow-up was assessed to be low quality for the majority of studies, with $61.3 \%$ (19/31) of studies assessing patients at $<12$ months of age. 


\section{Maternal and pregnancy characteristics}

The average maternal age and gestational age at diagnosis was 28.7 years (Table 2). The mean gestational age at diagnosis was 25.0 weeks' (range 17-34) and the mode gestational age was 24 weeks'. The indication for scan was not described in the majority of studies. Haematological/ thrombophilia testing, TORCH testing and karyotype or microarray were not stated in the majority of cases, but when performed no results were positive. Approximately half of fetuses affected were female (48.7\%); one quarter were male (25.6\%) and one quarter had no sex stated (25.6\%).

\section{Imaging}

All patients were initially diagnosed by ultrasound scan (US) with the majority $(71 / 78$, 91.0\%) also undergoing magnetic resonance imaging (MRI) (Figure 5). Identification of a hypoechogenic/ heemorrhagic/ cystic area in the posterior fossa was present in all cases. Visualisation of a likely thrombus within the echogenic area was present in 35 cases (44.9\%). The majority of studies did not provide size of either the hemorrhagic area or thrombus. The likely thrombus was visualised on MRI most commonly (21 cases, $26.9 \%)$; six cases were visualised on US only (7.7\%) and in eight cases (10.3\%) both MR and US visualised the likely thrombus. Compression of other brain structures was described in 22 cases (28.2\%) and ventriculomegaly was present in 13 cases (16.7\%).

Other findings included polyhydramnios in four cases ${ }^{11} 24$ (5.1\%), hydrops in two cases $^{8} 11(2.6 \%)$, and one case $^{7}(1.3 \%)$ in which a migrational disorder with disproportion of cerebral hemisphere size, abnormal grey matter thickening and 
sulcation with a schizencephaly/ polymicrogyria appearance was described on antenatal MRI. Repeat or sequential imaging was performed in 52 patients (66.7\%).

As Figure 6 shows, the majority of lesions either decreased in size (20 patients, 38.5\%) or completely resolved and were no longer visible (17 patients, $32.7 \%)$; of those that did not decrease, nine were stable or unchanged (17.3\%) and six (11.5\%) increased in size.

\section{Pregnancy and neonatal outcomes}

Three quarters of women chose to continue the pregnancy $(58 / 78,74.4 \%)$ and one quarter $(20 / 78,25.6 \%)$ chose to end the pregnancy (Table 3$)$. In women choosing to end the pregnancy, the average gestational age at diagnosis was 24.3 weeks. In these pregnancies, $25 \%(5 / 20)$ of fetuses had ventriculomegaly and one (5\%) had hydrops. Sixty percent of women choosing to terminate did so shortly after diagnosis and therefore had no further imaging (12/20). Of the women who continued the pregnancy for a period before termination, 25\% (5/20) had an increase in the size of the mass on

repeat ultrasound scanning, $10 \%(2 / 20)$ had a stable mass and 5\% (1/20) had a decrease in the size of the mass.

In women choosing to continue the pregnancy, 52 (89.7\%) experienced a livebirth and $6(10.3 \%)$ experienced a perinatal death: an intrauterine death occurred in two cases (3.4\%) and a neonatal death in four cases (6.9\%). The intrauterine deaths occurred at 23 and 26 weeks' gestation, following initial diagnosis but prior to any follow-up imaging. Maternal complications of pregnancy were not described in most studies. Mode of delivery was not stated in $17 / 52$ (32.7\%) of cases. When stated, delivery by caesarean section occurred in $60 \%$ of cases, and vaginal delivery occurred in $40 \%$ of 
cases. Decision-making regarding mode of delivery was generally not discussed in studies. Gestational age at delivery was not stated in 11 cases; in 41 cases where stated, the average gestational age at delivery was 37.9 weeks' (range 32-41 weeks).

In 14/52 (26.9\%) neonates tested for haematological/ thrombophilia disorders, no positive results were found. Postnatal MR imaging showed thrombus still present in 15 cases (44.1\%) and complete resolution with normal imaging in 15 cases (44.1\%). Other findings on postnatal MRI were: hydrocephalus ${ }^{10}$ (2), frontal parenchymal necrosis $^{24}(1)$ and schizencephaly/ polymicrogyria microencephaly of the left cerebral hemisphere $^{7}$ (1 - also noted on antenatal imaging).

The average age at follow up was 16.4 months (median age 12 months), ranging from birth to 6 years (Figure 7$)$. In two cases $(2 / 52,3.8 \%)$ the neonatal or childhood outcome was not stated. The neonatal or childhood outcome was described as good or "normal" in the majority of survivors $(44 / 50,88.0 \%)$. Abnormalities described in six cases (12.0\%) were: speech delay (2 - assessed at two years and five years), speech delay with likely autistic spectrum disorder (1 - assessed at 18 months), developmental delay (2 - assessed at 18 months and five years) and left spastic hemiparesis with inability to walk at 18 months (1). In all three cases of speech delay ${ }^{10}$, the lesion had resolved antenatally. One case of developmental delay ${ }^{10}$ was associated with antenatal increase of the lesion size and progressive ventriculomegaly. A second case of developmental delay ${ }^{7}$ was associated with the previously described finding of schizencephaly/ polymicrogyria microencephaly of the left cerebral hemisphere. The case of left spastic hemiparesis ${ }^{20}$ was associated with an "enormous heterogenic posterior collection with important anterior displacement of the brain and brainstem" 
on antenatal imaging; at birth a decompression surgery was performed on day 1 due to concerns regarding intracranial hemorrhage (decreased haemoglobin, disseminated intravascular coagulation, worsening neurology). At 18 months, a mild left spastic hemiparesis and inability to walk was described; neuropsychological testing showed normal cognitive development in the child. 


\section{$\underline{\text { Discussion }}$}

The differential diagnosis of a hypoechogenic mass in the posterior fossa of a fetus includes tumour, cyst, megacisterna magna and hemorrhage. Fetal intracranial hemorrhage most commonly occurs in the intraventricular space and hemorrhage in the posterior fossa is rare ${ }^{36}$. The incidence of fetal DST is unknown; this systematic review has found 78 cases in the medical literature although, given the average gestation of diagnosis and tendency towards resolution in pregnancy, it seems likely that some cases may occur without antenatal detection. In published case series of neonatal DST diagnosed following investigations for neurological symptoms (most commonly seizures), symptoms and imaging confirming DST often occurs close to birth - in one study ${ }^{37}$ at an average of 4.4 days of life (range one hour to 19 days) and in another study ${ }^{38}$ at an average of 1.5 days of life (range 0-28 days). The diagnosis of neonatal DST at such an early age could, in fact, represent undetected fetal DST. In the neonatal and paediatric population, associations with trauma, asphyxia, coagulopathy, polycythaemia and infection have been suggested ${ }^{2}$. However, in the fetal population, we could find no evidence that maternal or neonatal coagulopathy, infection or trauma played a role. It has been suggested that anatomical malformations of the dural sinus may occur embryologically ${ }^{3}$, leading to disturbance of blood flow and modification of the vascular endothelium. Although a male predominance has been reported in the neonatal and paediatric population ${ }^{3}$, we found a female predominance - where fetal sex was stated, approximately two thirds $(38 / 58,65.5 \%)$ were female and one third (20/58, 34.5\%) were male.

This systematic review found that the majority of hypoechogenic lesions either decreased in size or completely resolved antenatally (together $37 / 52,71.2 \%$ ) and 
almost half of postnatal MRIs performed (15/34, 44.1\%) showed no remaining lesion. Neonatal and paediatric outcomes - usually assessed by neurological examination were described as "normal" in $85 \%$ of surviving cases. The three cases with worst outcomes described (developmental delay, spastic hemiparesis) all had nonreassuring antenatal imaging: worsening ventriculomegaly ${ }^{10}$, schizencephaly/ polymicrogyria $^{7}$ and an extremely large lesion with compression of the whole brain and brainstem ${ }^{20}$. It therefore seems logical that if these findings are detected antenatally the prognosis may be more guarded.

Although several case reports of this condition discussed other published case reports known to the authors, this is the first systematic review of this topic. It therefore is the most comprehensive attempt to date of summarising the literature in this condition. However, there still may be missing data and a publication bias may exist whereby only cases with particular characteristics are chosen for publication. As shown in Figure 7, the length of follow-up within included studies was highly variable, from birth to six years. As Table 3 shows, the average age at follow up was 14.6 months for children with normal outcomes, compared to 30 months for those with abnormal outcomes. It is possible that neurological sequalae, particularly cognitive and behavioural outcomes, could be underestimated by the majority of studies included in this review. 


\section{$\underline{\text { Conclusion }}$}

Fetal dural sinus thrombosis is a rare condition which can be detected antenatally by visualisation of an echogenic posterior fossa mass (hemorrhage) containing a focal hyperechoic area within (thrombosis). Prenatal MRI may be beneficial in visualising the thrombus and confirming the diagnosis. No association with maternal or neonatal coagulopathy, infection or trauma is seen. Ten percent of cases experience in-utero or neonatal death. In survivors, the majority of cases reduce in size or completely resolve in pregnancy and $85 \%$ are reported to have a good outcome. However, further evidence is needed regarding long-term neurocognitive sequelae. 


\section{$\underline{\text { References }}$}

1. Moher D, Liberati A, Tetzlaff J, Altman DG. Preferred reporting items for systematic reviews and meta-analyses: The PRISMA statement. Int J Surg. 2010;8(5):336-341. doi:10.1016/j.jjsu.2010.02.007

2. Medlock M, Olivero W, Hanigan W, Wright R, Winek S. Children with Cerebral Venous Thrombosis Diagnosed with Magnetic Resonance Imaging and Magnetic Resonance Angiography. Neurosurgery. 1992;31(5):870-876. doi:10.1017/СBO9781107415324.004

3. Barbosa M, Mahadevan J, Weon YC, et al. Dural sinus malformation (DSM) with giant lakes, in neonates and infants. Review of 30 consecutive cases. Interv Neuroradiol. 2003;9(4):407424. doi:10.1177/159101990300900413

4. Murad MH, Sultan S, Haffar S, Bazerbachi F. Methodological quality and synthesis of case series and case reports. BMJ Evidence-Based Med. 2018;23:60-63.

5. Asai H, Okamoto T, Tsuchida E, Nohara F, Nagaya K. Thrombosed Dural Sinus Malformation in a Fetus : A Case Report. J Neuroimaging. 2014;24:603-606. doi:10.1111/jon.12099

6. Breysem L, Witters I, Spitz B, Moerman P, Smet MH. Fetal Magnetic Resonance Imaging of an Intracranial Venous Thrombosis. Fetal Di. 2006;21:13-17. doi:10.1159/000089041

7. Byrd SE, Abramowicz JS, Kent P, Kimura RE, Elias D, Heydeman PT. Fetal MR imaging of posterior intracranial dural sinus thrombosis : a report of three cases with variable outcomes. Pediatr Radiol. 2012;42:536-543. doi:10.1007/s00247-011-2287-9

8. Cho HJ, Jung EJ, Byun JM, et al. Thrombosed Fetal Dural Sinus Malformation: Correlation Between Prenatal Ultrasound and Autopsy Findings. Fetal Pediatr Pathol. 2018;37(4):287-295.

9. Clode N, Gouveia R, Graça LM. Prenatal diagnosis of thrombosis of the dural sinuses. Int J Gynecol Obstet. 2005;91(2):172-174. doi:10.1016/j.ijgo.2005.07.016

10. Corral E, Stecher X, Malinger G, Ochoa JH, de Catte L, Sepulveda W. Thrombosis of the torcular herophili in the fetus: A series of eight cases. Prenat Diagn. 2014;34(12):1176-1181. doi:10.1002/pd.4453

11. Delmas HL, Winer N, Gallot D, et al. Prenatal diagnosis of thrombosis of the dural sinuses: Report of six cases, review of the literature and suggested management. Ultrasound Obstet Gynecol. 2008;32(2):188-198. doi:10.1002/uog.5348

12. Ebert M, Esenkaya A, Huisman TAGM, et al. Multimodality, anatomical, and diffusion-weighted 
fetal imaging of a spontaneously thrombosing congenital dural sinus malformation. Neuropediatrics. 2012;43(5):279-282. doi:10.1055/s-0032-1324795

13. Fanou EM, Reeves MJ, Howe DT, et al. In utero magnetic resonance imaging for diagnosis of dural venous sinus ectasia with thrombosis in the fetus. Pediatr Radiol. 2013;43(12):15911598. doi:10.1007/s00247-013-2745-7

14. Gao J, Liu J, Zhou X, et al. Spontaneous resolution of a fetal dural sinus thrombosis: One case report and review of the literatures. Int J Fertil Steril. 2012;5(4):259-262.

http://www.embase.com/search/results?subaction=viewrecord\&from=export\&id=L365167391 \%5Cnhttp://www.ijfs.ir/library/upload/article/af_77244655343723343352332253244435442253 33Gao 11.pdf.

15. Gicquel JM, Potier A, Sitruk S, Girard N. Normal outcome after prenatal diagnosis of thrombrosis of the torcular Herophili. Prenat Diagn. 2000;20(10):824-827. doi:10.1002/10970223(200010)20:10<824::AID-PD926>3.0.CO;2-G

16. Görkem SB, Doğanay S, İkizceli T, Tokmak TT, Yıkılmaz A, Coşkun A. US and MRI findings of fetal dural sinus thrombosis: Report of two cases. Child's Nerv Syst. 2013;29(12):2317-2319. doi:10.1007/s00381-013-2212-7

17. Grangé G, LeTohic A, Merzoug V, Adamsbaum C. Prenatal demonstration of afferent vessels and progressive thrombosis in a torcular malformation. Prenat Diagn. 2007;27(7):670-673. doi:10.1002/pd.1744

18. Grigoriadis S, Cohen JE, Gomori JM. Prenatal thrombosis of torcular herophili with spontaneous resolution and normal outcome. J Neuroimaging. 2008;18(2):177-179. doi:10.1111/j.1552-6569.2007.00166.x

19. Has R, Esmer AC, Kalelioglu I, Yuksel A, Pata O, Demirbas R. Prenatal diagnosis of torcular herophili thrombosis: Report of 2 cases and review of the literature. $J$ Ultrasound Med. 2013;32(12):2205-2211. doi:10.7863/ultra.32.12.2205

20. Jenny B, Zerah M, Swift D, et al. Giant dural venous sinus ectasia in neonates. J Neurosurg Pediatr. 2010;5(5):523-528. doi:10.3171/2009.12.PEDS0862

21. Jung E, Won HS, Kim SK, et al. Spontaneous resolution of prenatally diagnosed dural sinuS thrombosis: A case report. Ultrasound Obstet Gynecol. 2006;27(5):562-565. doi:10.1002/uog.2764 
22. Legendre G, Picone O, Levaillant J, et al. Prenatal diagnosis of a spontaneous dural sinus thrombosis. Prenat Diagn. 2009;29:808-813. doi:10.1002/pd

23. McInnes M, Fong K, Grin A, et al. Malformations of the fetal dural sinuses. Can J Neurol Sci. 2009;36(1):72-77. doi:10.1017/S031716710000634X

24. Merzoug V, Flunker S, Drissi C, et al. Dural sinus malformation (DSM) in fetuses. Diagnostic value of prenatal MRI and follow-up. Eur Radiol. 2008;18(4):692-699. doi:10.1007/s00330007-0783-y

25. Ochiai D, Miyakoshi K, Miwa T, et al. Prenatal diagnosis of thrombosed dural sinus malformation with periorbital hemangioma: A case report. Eur J Obstet Gynecol Reprod Biol. 2016;198:157-159. doi:10.1016/j.ejogrb.2015.09.035

26. Özkan MB, Bilgici MC, Çelik H, Aygun C. Prenatal diagnosis of torcular herophili thrombosis with unfavored outcome and review of the literature. Egypt J Radiol Nucl Med. 2016;47(1):335339. doi:10.1016/j.ejrnm.2015.10.004

27. Pandey V, Dummula K, Parimi P. Antenatal thrombosis of torcular herophili presenting with anemia, consumption coagulopathy and high-output cardiac failure in a preterm infant. $J$ Perinatol. 2012;32(9):728-730. doi:10.1038/jp.2011.161

28. Rayssiguier R, Dumont C, Flunker S, Couture A, Boulot P, Prodhomme O. Thrombosis of torcular herophili: Diagnosis, prenatal management, and outcome. Prenat Diagn. 2014;34(12):1168-1175. doi:10.1002/pd.4448

29. Schwartz N, Monteagudo A, Bornstein E, Timor-Tritsch IE, Zagzag D, Kudla M. Thrombosis of an ectatic torcular herophili: Anatomic localization using fetal neurosonography. J Ultrasound Med. 2008;27(6):989-991. doi:10.7863/jum.2008.27.6.989

30. Simsek Y, Oztanir N, Sigirci A, et al. Spontaneous resolution of fetal dural sinus thrombosis following term delivery of a live infant. Ultrasound Obstet Gynecol. 2012;40(5):614-615. doi:10.1002/uog.12265

31. Spampinato MV, Hardin V, Davis M, Chang E, Rumboldt Z. Thrombosed fetal dural sinus malformation diagnosed with magnetic resonance imaging. Obstet Gynecol. 2008;111(2 PART 2):569-572. doi:10.1097/01.AOG.0000289227.12531.03

32. Keirsbilck J Van, Naulaers G, Cannie M, et al. Prenatal diagnosis of a dural sinus thrombosis with favorable outcome. Prenat Diagn. 2007;27:1056-1058. doi:10.1002/pd 
33. Visentin A, Falco P, Pilu G, et al. Prenatal diagnosis of thrombosis of the dural sinuses with real-time and color Doppler ultrasound. Ultrasound Obstet Gynecol. 2001;17(4):322-325. doi:10.1046/j.1469-0705.2001.00372.x

34. Wilson E, Edwards L. Prenatal diagnosis of fetal dural sinus thrombosis with postnatal resolution: A case report. Aust New Zeal J Obstet Gynaecol. 2018;58:86.

35. Xia W, Hu D, Xiao P, Yang W, Chen X. Dural Sinus Malformation Imaging in the Fetus: Based on 4 Cases and Literature Review. J Stroke Cerebrovasc Dis. 2018;27(4):1068-1076. doi:10.1016/j.jstrokecerebrovasdis.2017.11.014

36. Ghi T, Simonazzi G, Perolo A, et al. Outcome of antenatally diagnosed intracranial hemorrhage: Case series and review of the literature. Ultrasound Obstet Gynecol. 2003;22(2):121-130. doi:10.1002/uog.191

37. Shevell MI, Silver K, O'Gorman AM, Watters G V, Montes JL. Neonatal dural sinus thrombosis. Pediatr Neurol. 1989;5(3):161-165. doi:10.1016/0887-8994(93)90093-R

38. Berfelo FJ, Kersbergen $\mathrm{KJ}$, Van Ommen $\mathrm{CH}$, et al. Neonatal cerebral sinovenous thrombosis from symptom to outcome. Stroke. 2010;41(7):1382-1388.

doi:10.1161/STROKEAHA.110.583542 


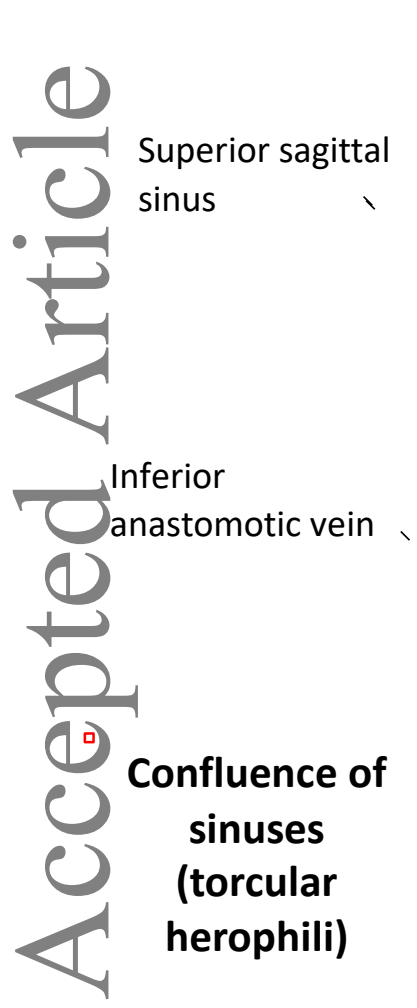
Superior
Superior cerebral
anastomotic vein
veins
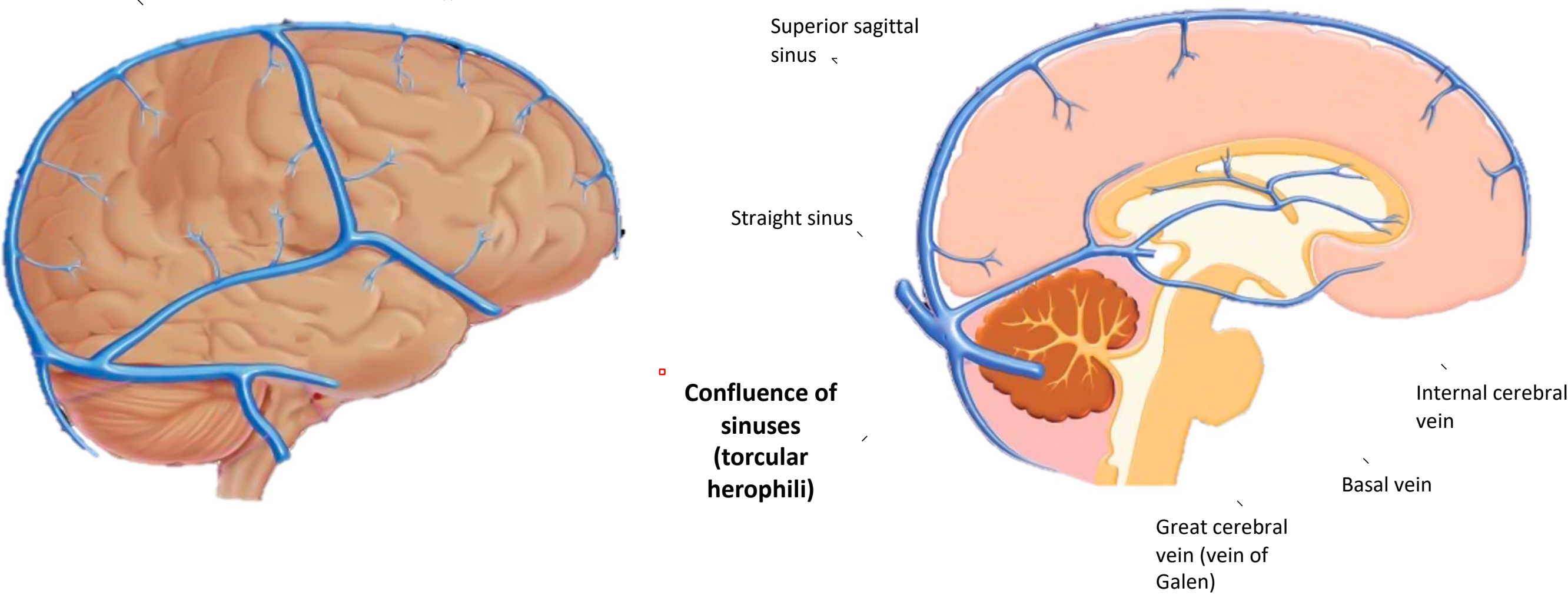


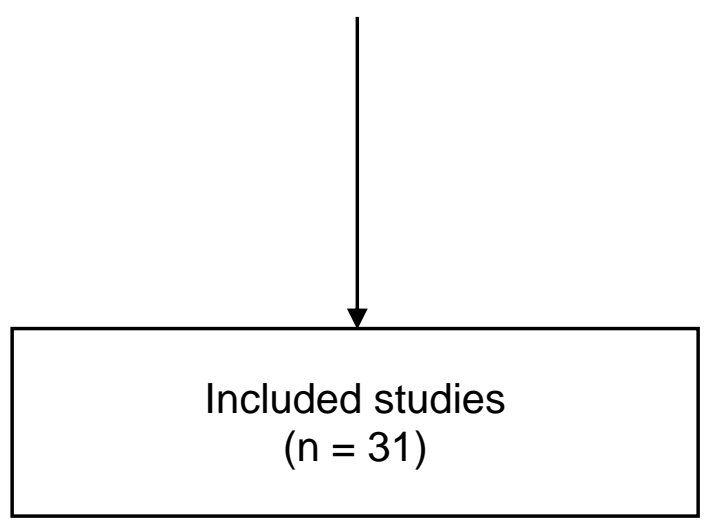

Full-text articles excluded $(n=12)$

- Neonatal/ paediatric population ( $\mathrm{n}$ $=8)$

- Insufficient information

(conference abstract or full text unavailable) $(n=2)$

- Thrombosis not confirmed $(n=1)$

- Duplicate study $(n=1)$

Figure 3: Flow diagram of study selection adapted from PRISMA $2009^{1}$
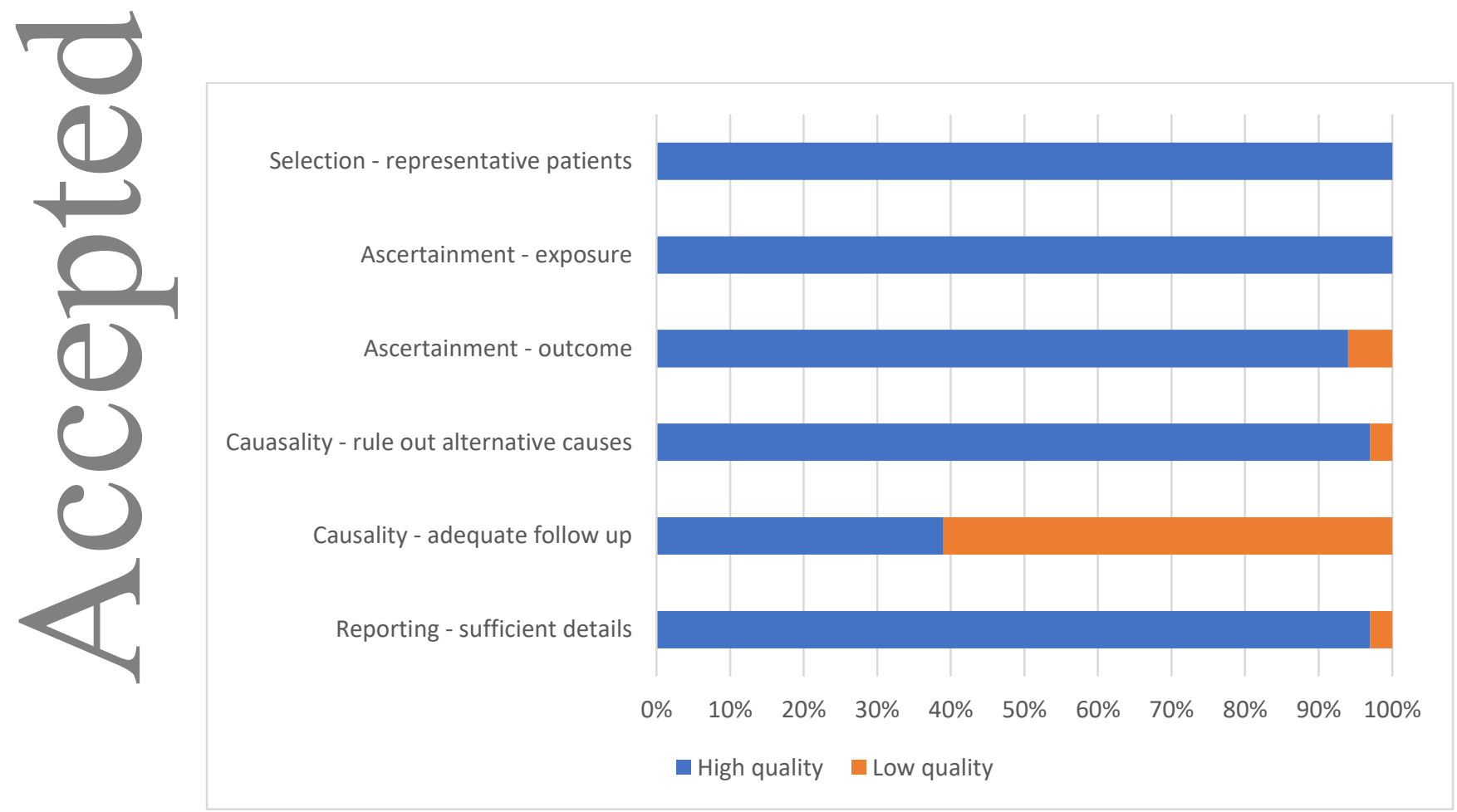

Figure 4: Quality assessment of studies using the Murad tool ${ }^{4}$ for case series and case reports 
imaging at day 13 , high-intensity signalling corresponding to thrombosis of torcular herophili and straight sinus

(Reproduced with permission from Rayssiguier et al $2014^{28}$ ).

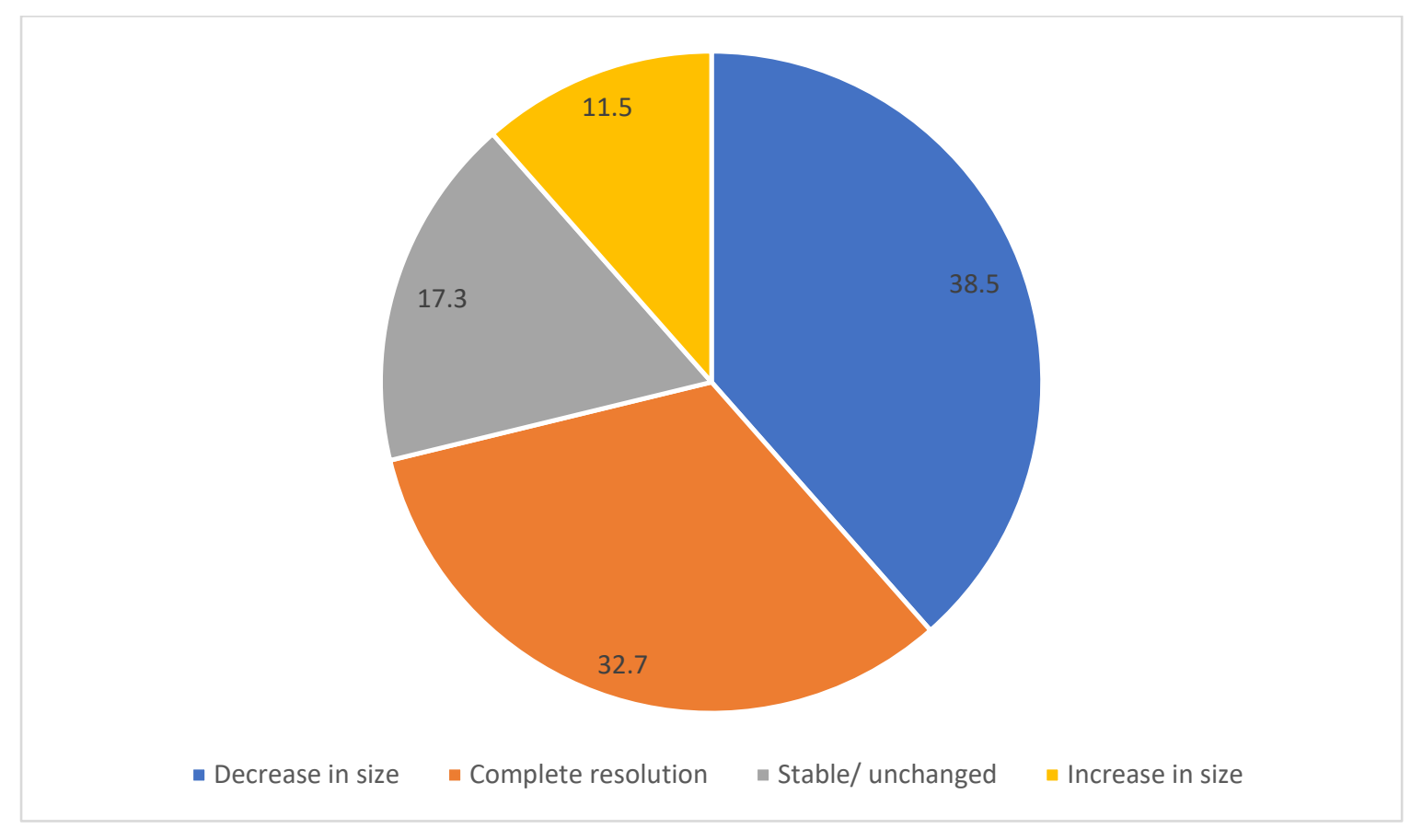

Figure 6: Change in size of echogenic lesion over serial scans for 52 patients (\%) 
0

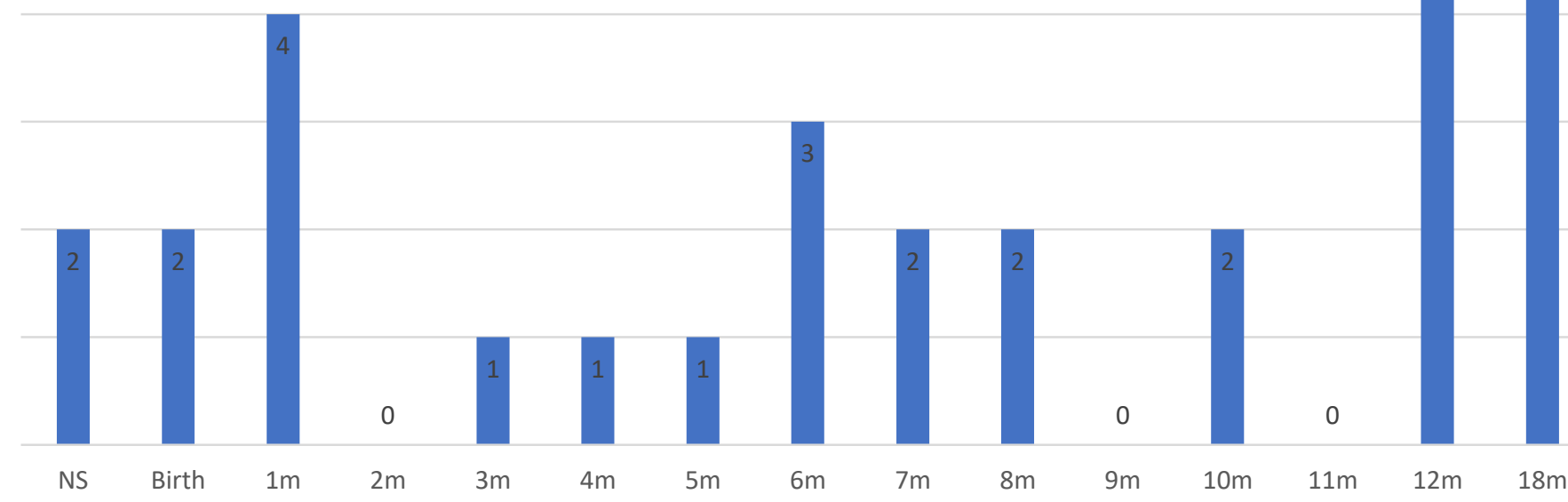

Figure 7: Length of follow up of patients

Bars show number of patients (n)

NS: not stated, m: months, y: years

\begin{tabular}{|l|l|l|}
\hline First author and year of publication & Study design & Number of patients \\
\hline Asai $2014^{5}$ & Case report & 1 \\
\hline Breysem $2006^{6}$ & Case report & 1 \\
\hline Byrd $2012^{\prime}$ & Case reports & 3 \\
\hline Cho $2018^{8}$ & Case reports & 2 \\
\hline Clode $2005^{9}$ & Case report & 1 \\
\hline Corral $2014^{10}$ & Case series & 8 \\
\hline Delmas $2008^{11}$ & Case series & 6 \\
\hline Ebert $2012^{12}$ & Case report & 1 \\
\hline Fanou $2013^{13}$ & Case series & 8 \\
\hline Gao $2012^{14}$ & Case report & 1 \\
\hline Gicquel $2000^{15}$ & Case report & 1 \\
\hline Görkem $2013^{16}$ & Case reports & 2 \\
\hline & & \\
\hline
\end{tabular}




\begin{tabular}{|c|c|c|}
\hline Grangé $2007^{11}$ & Case report & 1 \\
\hline Grigoriadis $2008^{18}$ & Case report & 1 \\
\hline Has $2013^{19}$ & Case reports & 2 \\
\hline Jenny $2010^{20}$ & Case report & 1 \\
\hline Jung $2006^{21}$ & Case report & 1 \\
\hline Legendre $2009^{22}$ & Case report & 1 \\
\hline Mclnnes $2009^{23}$ & Case report & 1 \\
\hline Merzoug $2008^{24}$ & Case series & 13 \\
\hline Ochiai $2016^{25}$ & Case report & 1 \\
\hline Ozkan $2016^{26}$ & Case report & 1 \\
\hline Pandey $2012^{2 \prime}$ & Case report & 1 \\
\hline Rayssiguier $2014^{28}$ & Case series & 8 \\
\hline Schwartz $2008^{29}$ & Case report & 1 \\
\hline Simsek $2012^{30}$ & Case report & 1 \\
\hline Spampinato $2008^{31}$ & Case report & 1 \\
\hline VanKeirsbilck $2007^{32}$ & Case report & 1 \\
\hline Visentin $2001^{33}$ & Case reports & 3 \\
\hline Wilson $2018^{34}$ & Case report & 1 \\
\hline \multirow[t]{2}{*}{ Xia $2018^{35}$} & Case reports & 3 \\
\hline & TOTAL & 78 \\
\hline
\end{tabular}

Table 1: Included studies 


\begin{tabular}{|l|l|l|l|}
\hline & Mean & Range & Not stated \\
\hline Maternal age (years) & 28.7 & $19-40$ & 25 \\
\hline $\begin{array}{l}\text { Gestational age at diagnosis } \\
\text { (weeks) }\end{array}$ & 25.0 & $18-34$ & 0 \\
\hline & & & \\
\hline Health concerns n (\%) & Positive & Negative & Not stated \\
\hline $\begin{array}{l}\text { Haematological/ thrombophilia } \\
\text { testing n (\%) }\end{array}$ & $0(0)$ & $8(10.3)$ & $69(88.5)$ \\
\hline TORCH testing n (\%) & $0(0)$ & $32(41.0)$ & $46(59.0)$ \\
\hline Karyotype/ microarray n (\%) & $0(0)$ & $9(11.5)$ & $69(88.5)$ \\
\hline & & $6(7.7 \%)$ & $72(92.3)$ \\
\hline Fetal sex n (\%) & Male & Female & Not stated \\
\hline
\end{tabular}

Table 2: Maternal and pregnancy characteristics of 78 cases of fetal DST

*Maternal health concerns in one case: previous DVT and possible PE five years prior to pregnancy associated with COCP use; haematological/ thrombophilia testing negative COCP: combined oral contraceptive pill, DVT: deep vein thrombosis, PE: pulmonary embolism, TORCH: toxoplasmosis, rubella, cytomegalovirus, herpes simplex, and HIV (+/- parvovirus) 


\begin{tabular}{|c|c|c|}
\hline Pregnancy/ neonatal details & & $\mathrm{n}(\%)$ \\
\hline \multirow[t]{2}{*}{ Parental choice } & Continuing pregnancy & $58(74.4)$ \\
\hline & Termination of pregnancy & $20(25.6)$ \\
\hline \multicolumn{3}{|l|}{ For continuing pregnancies: } \\
\hline \multirow[t]{2}{*}{ Pregnancy outcome } & Livebirth & $52(89.7)$ \\
\hline & Perinatal death & $6^{*}(10.3)$ \\
\hline \multirow[t]{3}{*}{ Mode of delivery } & Vaginal & $14(24.1)$ \\
\hline & Caesarean & $21(36.2)$ \\
\hline & Not stated & $23(39.6)$ \\
\hline \multirow[t]{2}{*}{ Neonatal haematological/ thrombophilia testing } & Normal & $14(100)$ \\
\hline & Abnormal & $0(0)$ \\
\hline \multirow{3}{*}{ Neonatal MRI } & Thrombus visible & $15(44.1)$ \\
\hline & Normal imaging & $15(44.1)$ \\
\hline & Other & $4^{\mp}(11.8)$ \\
\hline \multirow[t]{3}{*}{ Neonatal/paediatric outcome } & Good outcome & $44(84.6)$ \\
\hline & Abnormalities & $6^{\dagger}(11.5)$ \\
\hline & Not stated & $2(3.8 \%)$ \\
\hline \multicolumn{3}{|l|}{ For non-continuing pregnancies } \\
\hline \multirow[t]{3}{*}{ Post-mortem confirmation of diagnosis } & Yes & $17(65.4)$ \\
\hline & No & 0 \\
\hline & Not performed & 9 (34.6) \\
\hline
\end{tabular}

Table 3: Pregnancy and neonatal outcomes

* Perinatal death: intrauterine death (2), neonatal death (4)

$\ddagger$ Other MRI findings: hydrocephalus (2), schizencephaly and/or polymicrogyria (1), frontal parenchymal necrosis (1)

${ }^{\dagger}$ Abnormalities: speech delay (3), developmental delay (2), autism (1- also had speech delay), left spastic hemiparesis with inability to walk (1). 